\title{
Inflammation: an important parameter in the search of prostate cancer biomarkers
}

Stefania Bergamini ${ }^{1 *}$, Elisa Bellei ${ }^{1}$, Luca Reggiani Bonetti ${ }^{2}$, Emanuela Monari ${ }^{1}$, Aurora Cuoghi ${ }^{1}$, Francesco Borelli ${ }^{4}$, Maria Chiara Sighinolfi ${ }^{4}$, Giampaolo Bianchi ${ }^{4}$, Tomris Ozben ${ }^{3}$ and Aldo Tomasi ${ }^{1}$

\begin{abstract}
Background: A more specific and early diagnostics for prostate cancer (PCa) is highly desirable. In this study, being inflammation the focus of our effort, serum protein profiles were analyzed in order to investigate if this parameter could interfere with the search of discriminating proteins between PCa and benign prostatic hyperplasia (BPH).

Methods: Patients with clinical suspect of PCa and candidates for trans-rectal ultrasound guided prostate biopsy (TRUS) were enrolled. Histological specimens were examined in order to grade and classify the tumor, identify BPH and detect inflammation. Surface Enhanced Laser Desorption/Ionization-Time of Flight-Mass Spectrometry (SELDIToF-MS) and two-dimensional gel electrophoresis (2-DE) coupled with Liquid Chromatography-MS/MS (LC-MS/MS) were used to analyze immuno-depleted serum samples from patients with PCa and BPH.

Results: The comparison between PCa (with and without inflammation) and BPH (with and without inflammation) serum samples by SELDI-ToF-MS analysis did not show differences in protein expression, while changes were only observed when the concomitant presence of inflammation was taken into consideration. In fact, when samples with histological sign of inflammation were excluded, 20 significantly different protein peaks were detected. Subsequent comparisons (PCa with inflammation vs PCa without inflammation, and BPH with inflammation vs BPH without inflammation) showed that 16 proteins appeared to be modified in the presence of inflammation, while 4 protein peaks were not modified. With 2-DE analysis, comparing PCa without inflammation vs PCa with inflammation, and $\mathrm{BPH}$ without inflammation vs the same condition in the presence of inflammation, were identified 29 and 25 differentially expressed protein spots, respectively. Excluding samples with inflammation the comparison between PCa vs BPH showed 9 unique PCa proteins, 4 of which overlapped with those previously identified in the presence of inflammation, while other 2 were new proteins, not identified in our previous comparisons.

Conclusions: The present study indicates that inflammation might be a confounding parameter during the proteomic research of candidate biomarkers of PCa. These results indicate that some possible biomarker-candidate proteins are strongly influenced by the presence of inflammation, hence only a well-selected protein pattern should be considered for potential marker of PCa.
\end{abstract}

Keywords: Inflammation, Prostate cancer biomarkers, Proteomics, SELDI-ToF-MS, 2-DE

\footnotetext{
* Correspondence: stefania.bergamini@unimore.it

'Department of Diagnostic Medicine, Clinic and Public Health, Proteomic Lab, University Hospital of Modena and Reggio Emilia, Via del Pozzo 71, 41124

Modena, Italy

Full list of author information is available at the end of the article
} 


\section{Background}

Despite the improvements in clinical and surgical practice, prostate cancer $(\mathrm{PCa})$ remains one of the most widespread cancers in males, with an unchanged mortality rate [1-4].

The serum marker currently used for the diagnosis of $\mathrm{PCa}$ is the prostate-specific antigen (PSA), which is not particularly reliable, having a predictive value estimated at $25 \%-35 \%$ in the range of $2.6-10 \mathrm{ng} / \mathrm{mL}$ [2]. Furthermore, benign conditions such as prostatitis and benign prostatic hyperplasia $(\mathrm{BPH})$ can lead to an increase in PSA levels causing false positive $[5,6]$. With the aim of improving accuracy in the detection, monitoring and distinction between benign conditions and $\mathrm{PCa}$, it is imperative to identify new and reliable molecular targets.

In recent years, proteomic techniques have achieved a rapid evolution, due to innovative experimental approaches and improvements in sensitivity, resolution and accuracy of the mass analysers. Several proteomic studies have been carried out on serum $[7,8]$, urine [9], biopsy tissue [10] and cell lines [11,12], with the purpose of identifying promising targets for the early detection of PCa. Unfortunately, the majority of the candidate biomarkers are still awaiting validation $[13,14]$. Other studies have been performed in the attempt to discriminate $\mathrm{PCa}$ from BPH. Adam and co-workers used the protein profiling technology approach coupled with an artificial intelligence data analysis algorithm to distinguish $\mathrm{PCa}$ from non-cancer forms [15]. In another study, Ornstein et al. reported serum proteomic patterns obtained by Surface Enhanced Laser Desorption/Ionization-Time of Flight-Mass Spectrometry (SELDI-ToF-MS) analysis to discriminate $\mathrm{PCa}$ from $\mathrm{BPH}$ when PSA level is between 2.5 and $15 \mathrm{ng} / \mathrm{mL}$, with the aim to decrease unnecessary prostate biopsies [16]. More recently, Ummanni et al. examined biopsy samples from $\mathrm{BPH}$ and $\mathrm{PCa}$ patients using two-dimensional gel electrophoresis (2-DE) followed by Matrix Assisted Laser Desorption/Ionization-Time of Flight-Mass Spectrometry analysis (MALDI-ToF-MS), to identify potential biomarkers that might differentiate the two clinical events [17].

In this study, in order to identify distinctive protein profiles able to unquestionably discriminate patients with a benign prostate condition from those with a malignant situation, the serum protein expression of $\mathrm{PCa}$ and $\mathrm{BPH}$ was investigated by proteomics.

Differently from previous publications, the benign states were considered $v s$ the pathological ones focusing on the co-existence of inflammation, since emergent research underline a tight link between chronic inflammation and endothelial activation in both PCa and BPH [18-20].

Cancer and inflammation are closely linked, so much that cancer patients show both local and systemic changes in inflammatory parameters. In some cancer types, inflammatory conditions are present before a malignant change occurs; otherwise, in different type of cancer, an oncogenic alteration generates an inflammatory microenvironment that induces the development of tumors [21]. In PCa and $\mathrm{BPH}$ conditions, inflammation is frequently evident in prostate biopsies, radical prostatectomy specimens and tissue resected for the treatment of BPH. For this reason, the inflammatory injury, and consequently its chemical mediators and protein products, should be taken into account in proteomic studies aimed to identify PCa biomarkers.

In our study, serum samples were depleted of highabundant proteins by immuno-chromatography and the depleted samples were analysed by SELDI-ToF-MS. This is a sensitive proteomic technique that analyses proteins on large scale in a relatively short time and therefore it is of help for the preliminary screening of complex samples and for biomarkers search. Subsequently, samples were analysed by 2-DE coupled with LC-MS/MS, in order to precisely identify relevant proteins.

\section{Results and discussion}

Cancer survival rates depend on the early detection of the disease: currently, PCa diagnosis is performed using digital rectal exploration (DRE), trans-rectal ultrasound guided prostate biopsy (TRUS), and by the measurement of serum PSA levels. PSA is a sensitive marker for the detection of PCa, however it is not cancer-specific; elevated serum PSA levels are also observed in benign enlargements of the prostate, such as $\mathrm{BPH}$ or prostatitis, and after biopsy [22].

In this study, the serum proteins associated with $\mathrm{PCa}$ were compared to $\mathrm{BPH}$, in order to identify distinctive protein profiles able to unquestionably discriminate patients with a malignant situation from those with a benign prostate condition. The study was conducted taking into consideration that inflammation is an intrinsic component of the cancer and $\mathrm{BPH}$.

Because high-abundance proteins present in serum can interfere with resolution and sensitivity of proteomics, by masking low concentration proteins, serum samples were depleted by immunoaffinity chromatography. This procedure reduces the complexity of serum samples and enriches low-abundance proteins; moreover, it offers the lowest co-depletion of untargeted proteins, proving to be the most advantageous depletion approach for serum preparation prior to proteomic studies [23].

The analysis was first carried out by SELDI-ToF-MS using the H50 ProteinChip surface, irrespective of the presence of inflammation. Under this condition, no differential expression of protein peaks was evident between PCa samples $(n=31)$ and BPH $(n=30)$.

Since inflammation is often associated to both $\mathrm{PCa}$ and $\mathrm{BPH}$, its influence on the serum protein profile was 
tested. Therefore, after exclusion of samples with histological signs of inflammation, protein spectra from patients with $\mathrm{PCa}$ were compared to $\mathrm{BPH}$ (10 and 11 patients respectively).

This comparison showed evident differences in the protein profile, leading to the identification of 20 differentially expressed protein peaks; in particular, 5 peaks resulted increased $(\mathrm{m} / \mathrm{z} 2325,2348,2373,2581,3104)$ and 15 peaks decreased $(\mathrm{m} / \mathrm{z}$ 6624, 6837, 9352, 9922, $13775,14031,14106,14473,14763,22668,28052$, 28242, 29018, 45350, 56390) in PCa compared to BPH (Table 1).

The specific protein expression of PCa with inflammation $v s$ the same condition in absence of inflammation were subsequently compared. In this case, 9 protein peaks differentially expressed were detected: 4 peaks were increased $(\mathrm{m} / \mathrm{z} 9352,9922,21739,29018)$ and 5 peaks were decreased $(\mathrm{m} / \mathrm{z} 2325,2348,3104,3215$, 17471 ) in the presence of inflammation. Notably, 6 protein peaks coincided with 6 of the 20 peaks differentially

\begin{tabular}{|c|c|c|c|c|}
\hline Peak & $\mathrm{m} / \mathrm{z}$ & $\begin{array}{l}\text { PCa intensity } \\
\text { peak }\end{array}$ & $\begin{array}{l}\text { BPH intensity } \\
\text { peak }\end{array}$ & $\begin{array}{l}t \text {-test } \\
\mathrm{p} \text {-value }\end{array}$ \\
\hline \multicolumn{5}{|c|}{ Increased } \\
\hline 1 & 2325 & 4.29 & 1.32 & 0.002 \\
\hline 2 & 2348 & 3.97 & 1.18 & 0.006 \\
\hline 3 & 2373 & 3.27 & 1.10 & 0.005 \\
\hline 4 & 2581 & 1.34 & 0.33 & 0.002 \\
\hline 5 & 3104 & 2.19 & 0.88 & 0.007 \\
\hline \multicolumn{5}{|c|}{ Decreased } \\
\hline 1 & 6624 & 17.63 & 24.54 & 0.037 \\
\hline 2 & 6837 & 2.37 & 3.19 & 0.010 \\
\hline 3 & 9352 & 1.84 & 2.38 & 0.033 \\
\hline 4 & 9922 & 0.44 & 0.66 & 0.048 \\
\hline 5 & 13775 & 1.21 & 1.67 & 0.049 \\
\hline 6 & 14031 & 2.76 & 4.98 & 0.001 \\
\hline 7 & 14106 & 1.67 & 2.66 & 0.005 \\
\hline 8 & 14473 & 0.55 & 0.85 & 0.0003 \\
\hline 9 & 14763 & 0.57 & 0.76 & 0.002 \\
\hline 10 & 22668 & 0.06 & 0.10 & 0.003 \\
\hline 11 & 28052 & 2.05 & 3.90 & 0.003 \\
\hline 12 & 28242 & 1.42 & 2.33 & 0.011 \\
\hline 13 & 29018 & 0.48 & 0.93 & 0.003 \\
\hline 14 & 45350 & 0.78 & 1.23 & 0.002 \\
\hline 15 & 56390 & 0.84 & 1.32 & 0.026 \\
\hline
\end{tabular}

Statistical analysis was performed by Student's t test. The table shows the $p$-values statistically significant $(p \leq 0.05)$. expressed in the comparison between $\mathrm{PCa}$ and $\mathrm{BPH}$ in the absence of inflammation (Table 2, peaks in italic).

The same approach was applied to $\mathrm{BPH}$ and 15 peaks were found to be differentially expressed when $\mathrm{BPH}$ samples with and without inflammation were compared: 5 increased $(\mathrm{m} / \mathrm{z} 2325,2348,2373,2581,3104)$ and 10 decreased (m/z 6433, 6624, 6837, 9352, 14031, 14106, $14473,22668,28052,45350)$ in the presence of inflammation. Particularly, all peaks differently expressed, except one $(\mathrm{m} / \mathrm{z}$ 6433), overlapped with peaks found also in the comparison between $\mathrm{PCa}$ and $\mathrm{BPH}$ in the absence of inflammation (Table 3, peaks in square brackets).

In summary, SELDI-ToF-MS analysis demonstrated that, in the absence of inflammation, 20 different protein peaks are expressed in $\mathrm{PCa}$ in respect to $\mathrm{BPH}$. Of these, only 4 peaks, highlighted in Table 4 (in bold) and shown in Figure 1, could potentially differentiate $\mathrm{PCa}$ from $\mathrm{BPH}$, since their expression is not altered by the presence of inflammation. The remaining 16 peaks (also found differentially expressed in presence of inflammation) seem to be strongly related to inflammation, hence they can not be used as markers of PCa (Table 4). The inflammatory process therefore appears to be a limiting factor in the search of biomarkers able to discriminate $\mathrm{PCa}$ from $\mathrm{BPH}$ and it has not be underrated, since it represents a key mechanism in the development and progression of both diseases [24]. Inflammation is often observed in tumors, with immune cell infiltration and activated stroma. For this reason, cancer patients frequently present changes in various systemic parameters, comprising alterations in the level of serum inflammatory

Table 2 Differentially expressed peaks in PCa with inflammation vs PCa without inflammation detected by SELDI-ToF-MS

\begin{tabular}{ccccc}
\hline Peak & $\mathbf{m} / \mathbf{z}$ & $\begin{array}{c}\text { PCa with } \\
\text { inflammation } \\
\text { intensity peak }\end{array}$ & $\begin{array}{c}\text { PCa without } \\
\text { inflammation } \\
\text { intensity peak }\end{array}$ & $\begin{array}{c}\boldsymbol{t} \text {-test } \\
\text { p-value }\end{array}$ \\
\hline Increased & & & & \\
1 & 9352 & 2.26 & 1.84 & 0.050 \\
2 & 9922 & 0.64 & 0.45 & 0.040 \\
3 & 21739 & 0.08 & 0.05 & 0.019 \\
4 & 29018 & 0.75 & 0.49 & 0.043
\end{tabular}

\section{Decreased}

$\begin{array}{lllll}1 & 2325 & 2.51 & 4.29 & 0.025 \\ 2 & 2348 & 2.28 & 3.97 & 0.044 \\ 3 & 3104 & 1.24 & 2.19 & 0.025 \\ 4 & 3215 & 1.49 & 1.96 & 0.024 \\ 5 & 17471 & 2.67 & 3.25 & 0.047\end{array}$

Statistical analysis was performed by Student's $t$ test. The table shows the $p$-values statistically significant $(p \leq 0.05)$. Protein peaks in italic: protein peaks found also in the comparison between PCa and BPH excluding samples with inflammation (Table 1). 
Table 3 Differentially expressed peaks in BPH with inflammation vs BPH without inflammation detected by SELDI-ToF-MS

\begin{tabular}{|c|c|c|c|c|}
\hline Peak & $\mathrm{m} / \mathrm{z}$ & $\begin{array}{c}\text { BPH with } \\
\text { inflammation } \\
\text { intensity peak }\end{array}$ & $\begin{array}{c}\text { BPH without } \\
\text { inflammation } \\
\text { intensity peak }\end{array}$ & $\begin{array}{c}t \text {-test } \\
p \text {-value }\end{array}$ \\
\hline \multicolumn{5}{|c|}{ Increased } \\
\hline 1 & [2325] & 3.28 & 1.32 & 0.016 \\
\hline 2 & [2348] & 3.34 & 1.84 & 0.013 \\
\hline 3 & [2373] & 2.93 & 1.10 & 0.009 \\
\hline 4 & [2581] & 1.06 & 0.33 & 0.007 \\
\hline 5 & [3104] & 1.74 & 0.88 & 0.037 \\
\hline \multicolumn{5}{|c|}{ Decreased } \\
\hline 1 & 6433 & 9.65 & 12.61 & 0.009 \\
\hline 2 & [6624] & 18.39 & 24.54 & 0.017 \\
\hline 3 & [6837] & 2.51 & 3.19 & 0.018 \\
\hline 4 & [9352] & 1.92 & 2.38 & 0.037 \\
\hline 5 & [14031] & 3.49 & 4.98 & 0.012 \\
\hline 6 & [14106] & 2.00 & 2.66 & 0.036 \\
\hline 7 & [14473] & 0.68 & 0.85 & 0.033 \\
\hline 8 & [22668] & 0.07 & 0.10 & 0.011 \\
\hline 9 & [28052] & 2.82 & 3.90 & 0.033 \\
\hline 10 & [45350] & 0.94 & 1.23 & 0.037 \\
\hline
\end{tabular}

Statistical analysis performed by Student's $t$ test. The table shows the $p$-values statistically significant $(p \leq 0.05)$. Protein peaks in square: protein peaks found also in the comparison between $\mathrm{PCa}$ and $\mathrm{BPH}$ excluding samples with inflammation (Table 1).

cytokines, acute-phase proteins and total albumin [25]. In fact, inflammation generates not only cancer-promoting microenvironment changes, but also systemic alterations that promote cancer progression [26]. Despite the evidence that inflammation is an intrinsic component of cancer, this fundamental aspect is often ignored in biomarker research studies.

The indications reported above and the preliminary results obtained in the present study by SELDI-ToF-MS analysis, suggested that inflammation could be a confounding factor in the identification of protein profiles able to discriminate between $\mathrm{PCa}$ and $\mathrm{BPH}$. Afterward, to verify this supposition, proteomic analysis was performed by 2-DE coupled with MS.

Representative 2-D gels obtained from depleted serum samples are reported in Figure 2. Inflammation-free PCa vs PCa with inflammation were first compared (first comparison); then, $\mathrm{BPH}$ was considered in the absence or presence of inflammation (second comparison), and finally the two conditions were compared with the exclusion of inflammation (third comparison). The differentially expressed protein spots are marked in the images by alphanumeric labels, that correspond to those reported in the first column of Tables 5, 6 and 7, respectively. The second column of Tables 5, 6 and 7 refers to the primary
Table 4 Comparison of peaks intensities differentially expressed in PCa vs BPH detected by SELDI-ToF-MS

\begin{tabular}{|c|c|c|c|c|c|}
\hline \multirow[t]{4}{*}{ Peak } & \multirow[t]{4}{*}{$\mathrm{m} / \mathrm{z}$} & \multicolumn{4}{|c|}{ Intensity peak } \\
\hline & & \multirow{2}{*}{\multicolumn{2}{|c|}{$\begin{array}{l}\text { PCA }(n=31) \\
\text { Inflammation }\end{array}$}} & \multirow{2}{*}{\multicolumn{2}{|c|}{$\begin{array}{l}\text { BPH }(n=30) \\
\text { Inflammation }\end{array}$}} \\
\hline & & & & & \\
\hline & & $\begin{array}{l}\text { Absent } \\
(n=10)\end{array}$ & $\begin{array}{l}\text { Present } \\
(n=21)\end{array}$ & $\begin{array}{l}\text { Absent } \\
(n=11)\end{array}$ & $\begin{array}{l}\text { Present } \\
(n=19)\end{array}$ \\
\hline 1 & 2325 & 4.30 & 2.51 & 1.32 & 3.28 \\
\hline 2 & 2348 & 3.97 & 2.28 & 1.84 & 3.34 \\
\hline 3 & 2373 & 3.28 & $1.95^{*}$ & 1.10 & 2.93 \\
\hline 4 & 2581 & 1.34 & $0.85^{*}$ & 0.33 & 1.06 \\
\hline 5 & 3104 & 2.20 & 1.24 & 0.88 & 1.74 \\
\hline 6 & 6624 & 17.63 & $18.93^{*}$ & 24.54 & 18.39 \\
\hline 7 & 6837 & 2.37 & $2.54^{*}$ & 3.19 & 2.51 \\
\hline 8 & 9352 & 1.84 & 2.26 & 2.38 & 1.92 \\
\hline 9 & 9922 & 0.44 & 0.64 & 0.66 & $0.52^{*}$ \\
\hline 10 & 13775 & 1.21 & $1.58^{*}$ & 1.67 & $1.57^{*}$ \\
\hline 11 & 14031 & 2.76 & $3.74^{*}$ & 4.98 & 3.49 \\
\hline 12 & 14106 & 1.67 & $2.14^{*}$ & 2.66 & 2.00 \\
\hline 13 & 14473 & 0.55 & $0.73^{*}$ & 0.85 & 0.68 \\
\hline 14 & 14763 & 0.57 & $0.66^{*}$ & 0.76 & $0.71^{*}$ \\
\hline 15 & 22668 & 0.06 & $0.08^{*}$ & 0.10 & 0.07 \\
\hline 16 & 28052 & 2.05 & $3.06^{*}$ & 3.90 & 2.82 \\
\hline 17 & 28242 & 1.42 & $1.88^{*}$ & 2.33 & $1.81^{*}$ \\
\hline 18 & 29018 & 0.48 & 0.75 & 0.93 & $0.68^{*}$ \\
\hline 19 & 45350 & 0.78 & $1.00^{*}$ & 1.23 & 0.94 \\
\hline 20 & 56390 & 0.84 & $1.24^{*}$ & 1.32 & $1.09^{*}$ \\
\hline
\end{tabular}

Protein peaks in bold: protein peaks discriminating $\mathrm{PCa}$ from $\mathrm{BPH}$.

${ }^{*}$ Differences not statistically significant.

accession number, derived from the UniProt knowledge database, the third column provides the complete name of each identified protein and column 4 reports the theoretical molecular weight (MW). Column 5 shows the highest ion scores obtained with MASCOT search engine, expressed as the probability that the observed match between the experimental data and the database sequence could be due to a random event. Column 6 indicates the total number of peptides that matched the identified proteins and the significant matches, while column 7 reports the total number of sequences and the number of significant sequences. Finally, the last column reports the protein expression change, indicated by arrows.

In the presence of inflammation, the first comparison showed 29 spots differentially expressed corresponding to 17 unique proteins (Table 5 and Figure 2B), while the second comparison showed 25 spots differentially expressed corresponding to 15 unique proteins (Table 6 and Figure 2D).

Ten unique proteins, corresponding to 20 and 19 spots in the first and second comparison respectively, were 

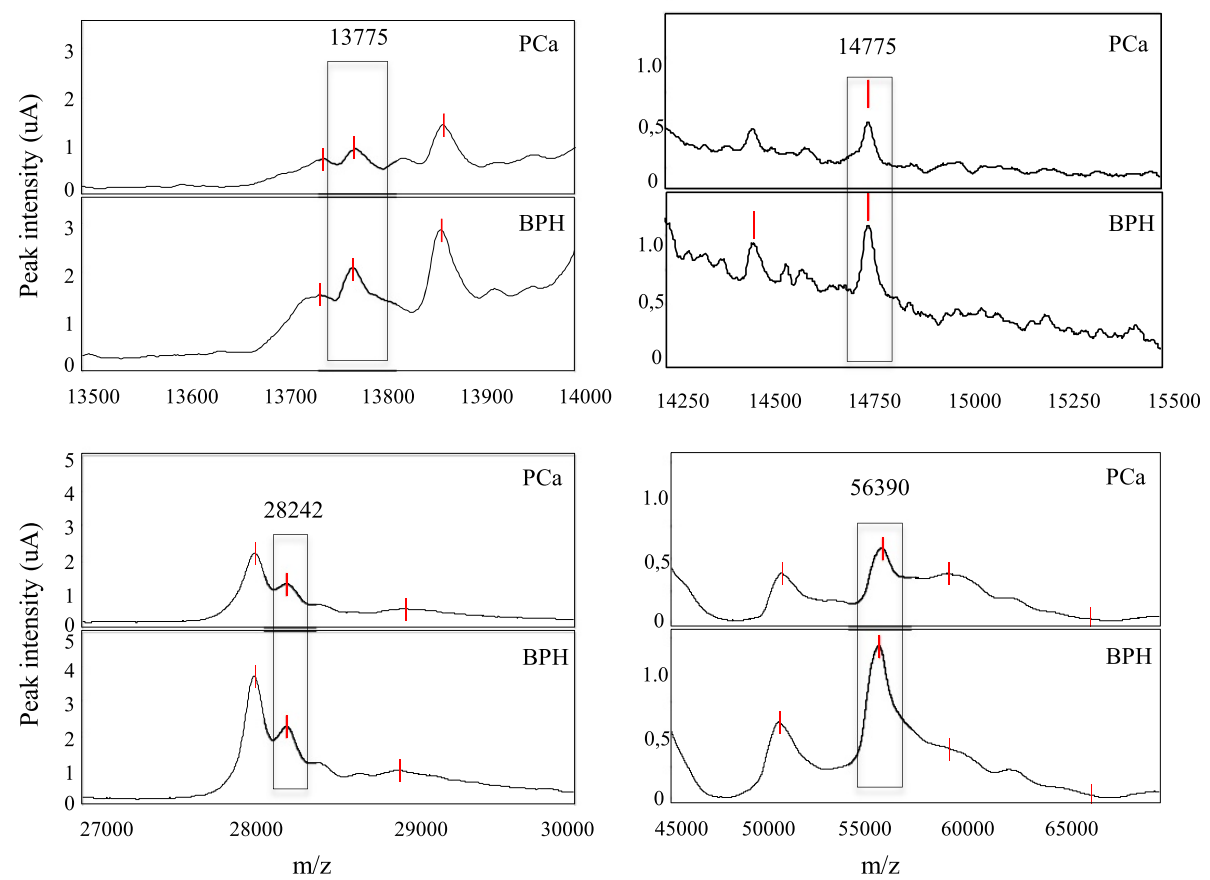

Figure 1 Representative spectra obtained by SELDI-ToF-MS analysis concerning the 4 statistically significant peaks detected with H50 ProteinChip Array.

found to be common to both $\mathrm{PCa}$ and $\mathrm{BPH}$ in the presence of inflammation (yellow labels in Figure $2 \mathrm{~B}$ and in 2D, respectively). Seven of these proteins resulted increased in both conditions: Complement factor B, Prothrombin, Beta-2-glycoprotein 1, Complement C3 fragment, Zincalpha-2-glycoprotein, Clusterin and Retinol binding protein. Apolipoprotein CIII appeared decreased in PCa and increased in $\mathrm{BPH}$, while Inter-alpha-trypsin inhibitor heavy chain and Haptoglobin resulted increased in PCa and decreased in BPH (Tables 5 and 6, proteins name in italic).

When the two conditions were compared in the absence of inflammation (third comparison), 9 unique proteins differentially expressed, corresponding to 16 spots, were found in $\mathrm{PCa}$ (Figure 2A and Table 7). Precisely, 4 resulted increased: Prothrombin, Complement C4-B, fragments of Complement C3 and Zinc-alpha-2-glycoprotein; while 5 were decreased: Hemopexin, Antithrombin-III, Pigment epithelium-derived factor, Haptoglobin and Serum Amyloid A-1 protein.

Serum Amyloid A-1 protein is an acute phase protein that is synthesized under the regulation of inflammatory cytokines during both acute and chronic inflammation [27]. In a recent study reported by Menschikowski et al., this protein is considered a circulating biomarker of inflammation during $\mathrm{BPH}$ development and $\mathrm{PCa}$ progression [28]. In our study, Serum Amyloid A-1 protein was found decreased in BPH without inflammation (Table 6) in accordance with the literature data, while in PCa patients this protein did not shown any changes.

As highlighted in Figure 2A (yellow labels) and in Table 7 (protein names in italic), in third comparison were found some proteins identified also in $\mathrm{PCa}$ and $\mathrm{BPH}$ in the presence of inflammation (probably inflammationlinked proteins), such as fragments of Complement C3, Prothrombin, Haptoglobin and Zinc-alpha-2-glycoprotein. This can be clearly explained since a certain degree of inflammation is always present in PCa.

The most interesting result observed in third comparison is the detection of 2 proteins, not identified in the previous comparisons, namely Hemopexin and Antithrombin-III, (Figure 2A, green labels and Table 7, protein names in bold).

Hemopexin (or $\beta_{1 \mathrm{~B}}$-glycoprotein) is a heme-binding serum protein with high carbohydrate content and immunoelectrophoretic identity. The most important physiological role of Hemopexin is to act as an antioxidant in case of heme overload, rather than to participate in iron metabolism [29]. In a recent work, Hemopexin $\mathrm{N}$-glycan profile was indicated to be of diagnostic value in hepatocellular carcinoma patients [30].

Antithrombin-III is a member of the serpin family and functions as an inhibitor of thrombin and other enzymes involved in the clotting cascade; moreover, it has been demonstrated to possess a potent antiangiogenic activity 


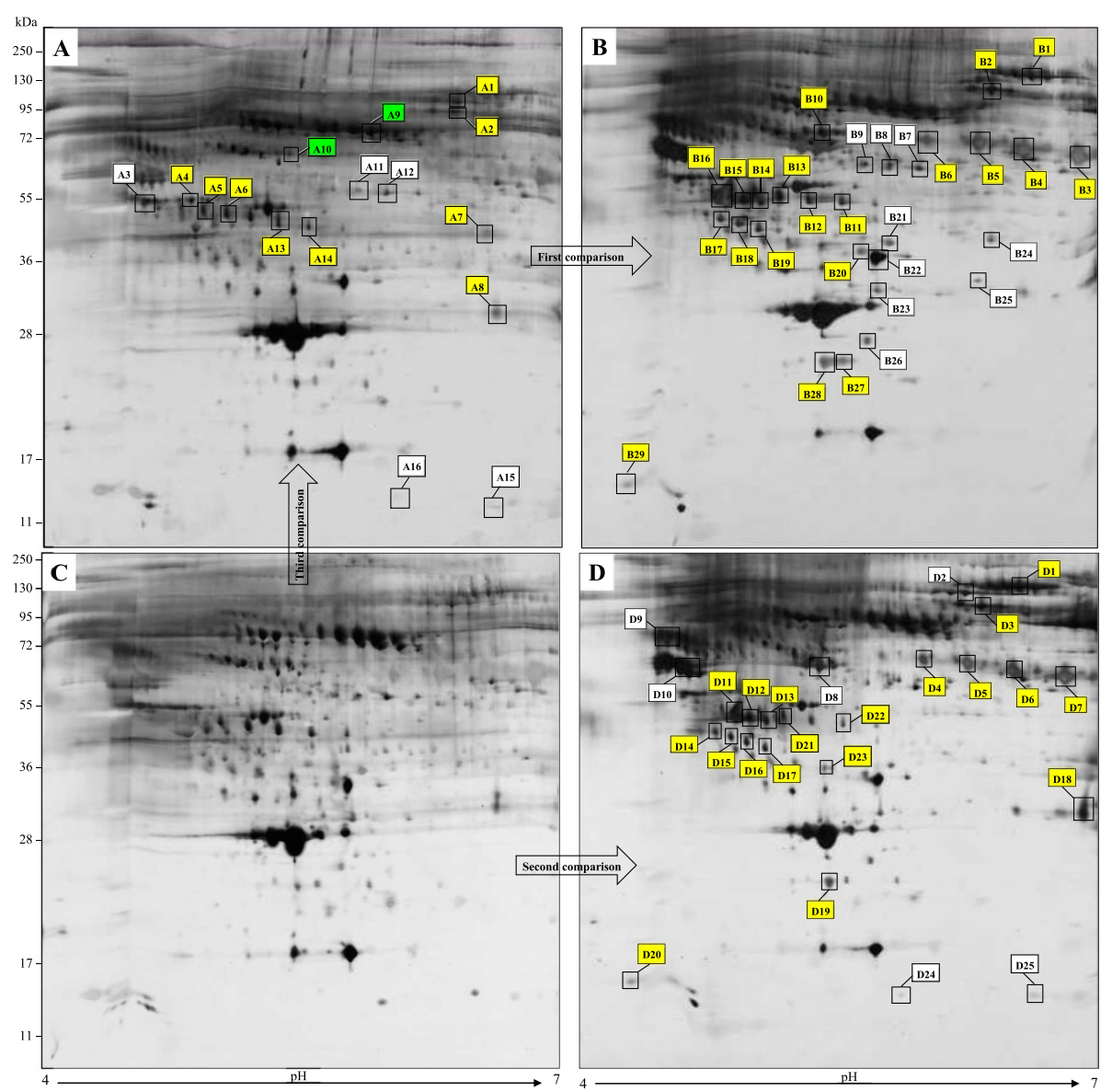

Figure 2 Bi-dimensional proteome maps of serum samples from PCa without (A) and with inflammation (B), and BPH in absence (C) and presence of inflammation (D). Proteins were resolved by IEF over the $\mathrm{pH}$ range 4-7, followed by 8-16\% gradient gel and visualized by Silver staining. Significant differentially expressed proteins are marked with alphanumeric labels, corresponding to those listed in Tables 5, 6 and 7. Yellow tags indicate the overlapped proteins detected in presence of inflammation in both PCa (B) and BPH (D) conditions. Some of these proteins were also revealed in PCa in absence of inflammation (A, third comparison). Additionally, in this latter situation, green labels represent proteins not previously identified in the first and second comparisons, namely in presence of inflammation.

and antitumor action [31]. Cao et al. have examined the expression of Antithrombin in benign and malignant prostate gland. They found that this protein was widely expressed in $\mathrm{PCa}$, but was gradually lost in tumors with high Gleason grade [32]. A decrease in plasma levels of Antithrombin-III is also reported in patients with colon and ovarian cancer, especially in presence of metastasis [33], other than in PCa [34]. In our study, we found a significantly lower expression of Antithrombin-III in $\mathrm{PCa}$ than the BPH. Hence, the local anti-angiogenic activity of Antithrombin-III may be partially lost in advanced stages of PCa.

The comparison of the protein profile between $\mathrm{PCa}$ and BPH by 2-DE showed several differentially expressed proteins, the majority of which could be related to the inflammatory process and not to the pathological condition. These results confirm those obtained by SELDIToF-MS analysis although it is not possible to perform a direct correspondence between the two techniques because the analytical conditions are different (pre-analytical sample treatment, detection of proteins in different mass range, use of selective chromatographic surface with the SELDI-ToF-MS technology).

\section{Conclusions}

This paper emphasizes the importance of considering inflammation in endeavours aimed to the discovery of specific markers capable to differentiate $\mathrm{PCa}$ from $\mathrm{BPH}$. Using two different proteomic techniques we have clearly demonstrated that, in the presence of inflammation, the majority of the differentially expressed protein peaks detected by SELDI-ToF-MS and of protein spots revealed by 2-DE analysis can't be considered discriminating markers of PCa. Therefore, the inflammatory process masks the detection of some proteins, which 
Table 5 Differentially expressed proteins in PCa without inflammation vs PCa with inflammation (UniProtKB database)

\begin{tabular}{|c|c|c|c|c|c|c|c|}
\hline Spot $n^{\circ}$. & Acc. $n^{\circ}$. & Protein full name & Mass (Da) & Score & $\mathrm{N}^{\circ}$ matchs/signif. matchs & $\mathrm{N}^{\circ}$ seq./signif. seq. & $\begin{array}{c}\text { Expression } \\
\text { change }\end{array}$ \\
\hline $\mathrm{B} 1$ & P00751 & Complement factor $B$ & 86847 & 445 & $212 / 60$ & $33 / 19$ & $\uparrow$ \\
\hline B2 & P00734 & Prothrombin & 71475 & 455 & $75 / 39$ & $15 / 7$ & $\uparrow$ \\
\hline B3 & P02749 & Beta-2-glycoprotein 1 & 39584 & 458 & $81 / 42$ & $17 / 8$ & $\uparrow$ \\
\hline B4 & P02749 & Beta-2-glycoprotein 1 & 39584 & 288 & $69 / 32$ & $14 / 12$ & $\uparrow$ \\
\hline B5 & P02749 & Beta-2-glycoprotein 1 & 39584 & 122 & $55 / 17$ & $11 / 8$ & $\uparrow$ \\
\hline B6 & P02749 & Beta-2-glycoprotein 1 & 39584 & 35 & $28 / 4$ & $6 / 3$ & $\uparrow$ \\
\hline B7 & P36955 & Pigment epithelium-derived factor & 46454 & 142 & $46 / 13$ & $11 / 8$ & $\uparrow$ \\
\hline B8 & P36955 & Pigment epithelium-derived factor & 46454 & 65 & $42 / 12$ & $13 / 5$ & $\uparrow$ \\
\hline B9 & P36955 & Pigment epithelium-derived factor & 46454 & 51 & $35 / 8$ & $13 / 7$ & $\uparrow$ \\
\hline B10 & Q14624 & Inter-alpha-trypsin inhibitor heavy chain $\mathrm{H} 4$ & 103521 & 375 & $152 / 47$ & $30 / 13$ & $\uparrow$ \\
\hline B11 & P00738 & Haptoglobin & 45861 & 110 & $83 / 21$ & $17 / 7$ & $\uparrow$ \\
\hline $\mathrm{B} 12$ & P00738 & Haptoglobin & 45861 & 236 & $99 / 28$ & $18 / 8$ & $\uparrow$ \\
\hline B13 & P00738 & Haptoglobin & 45861 & 138 & $97 / 16$ & $18 / 6$ & $\uparrow$ \\
\hline B14 & P25311 & Zinc-alpha-2-glycoprotein & 34465 & 104 & $24 / 9$ & $10 / 4$ & $\uparrow$ \\
\hline B15 & P01024 & Complement C3 (fragment) & 188569 & 104 & $49 / 8$ & $21 / 4$ & $\uparrow$ \\
\hline B16 & P01024 & Complement C3 (fragment) & 188569 & 2354 & $365 / 180$ & $38 / 27$ & $\uparrow$ \\
\hline B17 & P10909 & Clusterin & 53031 & 241 & $57 / 16$ & $10 / 4$ & $\uparrow$ \\
\hline B18 & P10909 & Clusterin & 53031 & 138 & $31 / 12$ & $7 / 3$ & $\uparrow$ \\
\hline B19 & P10909 & Clusterin & 53031 & 202 & $55 / 22$ & $11 / 7$ & $\uparrow$ \\
\hline B20 & Q14624 & Inter-alpha-trypsin inhibitor heavy chain $\mathrm{H} 4$ & 103521 & 41 & $13 / 3$ & $2 / 2$ & $\uparrow$ \\
\hline B21 & P02649 & Apolipoprotein E & 36246 & 398 & $125 / 43$ & $27 / 13$ & $\uparrow$ \\
\hline B22 & P02766 & Transthyretin & 15991 & 1086 & $165 / 71$ & $16 / 11$ & $\uparrow$ \\
\hline B23 & P02743 & Serum amyloid P-component & 25485 & 304 & $43 / 20$ & $8 / 6$ & $\uparrow$ \\
\hline B24 & O75636 & Ficolin-3 & 33395 & 205 & $71 / 24$ & $12 / 7$ & $\uparrow$ \\
\hline B25 & P36980 & Complement factor $\mathrm{H}$-related protein 2 & 31543 & 70 & $25 / 8$ & $6 / 4$ & $\uparrow$ \\
\hline B26 & O95455 & Apolipoprotein M & 21582 & 49 & $22 / 3$ & $7 / 3$ & $\uparrow$ \\
\hline B27 & P02753 & Retinol binding protein 4 & 23337 & 230 & $42 / 15$ & $7 / 5$ & $\uparrow$ \\
\hline B28 & P02753 & Retinol binding protein 4 & 23337 & 1071 & $154 / 74$ & $9 / 8$ & $\uparrow$ \\
\hline B29 & P02656 & Apolipoprotein C-III & 10846 & 84 & $10 / 4$ & $2 / 4$ & $\downarrow$ \\
\hline
\end{tabular}

Protein names in italic: proteins found also in the comparison between BPH without inflammation and BPH with inflammation (Table 6).

could be the real differential targets between the malignant and benign condition.

\section{Methods}

\section{Study population}

Ninety patients with clinical suspect of PCa (serum PSA elevation and/or palpable mass at DRE) and candidates for TRUS guided biopsy were enrolled. The recruitment was done at the Department of Urology, University Hospital of Modena and Reggio Emilia. Participants provided written informed consent and the local research Ethical Committee (Comitato Etico Provinciale di Modena) approved the study design.

The median patients age was 67 years (range 57-81). We excluded subjects with relevant systemic diseases or significant clinical events during the 6 months before the recruitment and patients that received hormonal treatment or radio-chemotherapy. All patients underwent a 12 months follow up.

\section{Histological examination and patients' classification}

All enrolled patients underwent to TRUS guided biopsy with a $16-G$ needle. A total of 12 samples (6 per side) were obtained from each biopsy. Each transrectal ultrasound performed included an assessment of prostatic diameter, the volume of the whole prostate, and the transition zone and capsular and seminal vesicle characteristics, as well as a morphological description of potential pathological features in the peripheral or transition zone. Each histological specimen was examined by two 
Table 6 Differentially expressed proteins in BPH without inflammation vs BPH with inflammation

\begin{tabular}{|c|c|c|c|c|c|c|c|}
\hline Spot $n^{\circ}$. & Acc. $n^{\circ}$. & Protein full name & Mass (Da) & Score & $\mathrm{N}^{\circ}$ matchs/signif. matchs & $\mathrm{N}^{\circ}$ seq./signif. seq. & $\begin{array}{c}\text { Expression } \\
\text { change }\end{array}$ \\
\hline D1 & P00751 & Complement factor $B$ & 86847 & 501 & $196 / 57$ & $34 / 15$ & $\uparrow$ \\
\hline D2 & P06396 & Gelsolin & 86043 & 301 & $141 / 37$ & $25 / 14$ & $\uparrow$ \\
\hline D3 & P00734 & Prothrombin & 71475 & 168 & $42 / 14$ & $12 / 5$ & $\uparrow$ \\
\hline D4 & P02749 & Beta-2-glycoprotein 1 & 39584 & 39 & $15 / 2$ & $5 / 2$ & $\uparrow$ \\
\hline D5 & P02749 & Beta-2-glycoprotein 1 & 39584 & 41 & $32 / 15$ & $7 / 4$ & $\uparrow$ \\
\hline D6 & P02749 & Beta-2-glycoprotein 1 & 39584 & 331 & $72 / 30$ & $13 / 9$ & $\uparrow$ \\
\hline D7 & P02749 & Beta-2-glycoprotein 1 & 39584 & 204 & $70 / 33$ & $13 / 7$ & $\uparrow$ \\
\hline D8 & P02774 & Vitamin-D binding protein & 54526 & 1679 & 283/149 & $32 / 28$ & $\uparrow$ \\
\hline D9 & P01011 & Alpha-1-antichymotrypsin & 47792 & 324 & $54 / 24$ & $11 / 8$ & $\uparrow$ \\
\hline D10 & P02765 & Alpha-2-HS-glycoprotein & 40098 & 273 & $96 / 38$ & $11 / 9$ & $\uparrow$ \\
\hline D11 & P01024 & Complement C3 (fragment) & 188569 & 700 & $210 / 73$ & $33 / 16$ & $\uparrow$ \\
\hline D12 & P01024 & Complement C3 (fragment) & 188569 & 1500 & $300 / 126$ & $42 / 23$ & $\uparrow$ \\
\hline D13 & P25311 & Zinc-alpha-2-glycoprotein & 34465 & 66 & $15 / 6$ & $6 / 3$ & $\uparrow$ \\
\hline D14 & P10909 & Clusterin & 53031 & 83 & $21 / 4$ & $8 / 2$ & $\uparrow$ \\
\hline D15 & P10909 & Clusterin & 53031 & 245 & $42 / 14$ & $8 / 4$ & $\uparrow$ \\
\hline D16 & P10909 & Clusterin & 53031 & 159 & $39 / 14$ & $8 / 6$ & $\uparrow$ \\
\hline D17 & P10909 & Clusterin & 53031 & 174 & $25 / 11$ & $6 / 3$ & $\uparrow$ \\
\hline D18 & P01024 & Complement C3 fragment & 188569 & 834 & $119 / 57$ & $16 / 10$ & $\uparrow$ \\
\hline D19 & P02753 & Retinol binding protein 4 & 23337 & 585 & $134 / 64$ & $9 / 9$ & $\uparrow$ \\
\hline D20 & P02656 & Apolipoprotein C-III & 10846 & 231 & $7 / 7$ & $2 / 2$ & $\uparrow$ \\
\hline D21 & P00738 & Haptoglobin & 45861 & 524 & $102 / 43$ & $15 / 10$ & $\downarrow$ \\
\hline D22 & P00738 & Haptoglobin & 45861 & 348 & $90 / 34$ & $17 / 9$ & $\downarrow$ \\
\hline D23 & Q14624 & Inter-alpha-trypsin inhibitor heavy chain $\mathrm{H} 4$ & 103521 & 222 & $30 / 19$ & $7 / 6$ & $\downarrow$ \\
\hline D24 & P0DJI8 & Serum amyloid A-1 protein & 13581 & 269 & $26 / 13$ & $10 / 5$ & $\downarrow$ \\
\hline D25 & PODJ8 & Serum amyloid A-1 protein & 13581 & 360 & $29 / 16$ & $10 / 5$ & $\downarrow$ \\
\hline
\end{tabular}

Protein names in italic: proteins found also in the comparison between PCa without inflammation and PCa with inflammation (Table 5).

pathologists, with the aim to recognize conditions of $\mathrm{PCa}$ and $\mathrm{BPH}$, besides the presence of inflammation. The histological criterion used to define inflammation was the presence of pathological infiltration of the prostatic tissue by inflammatory cells, evaluated by hematoxylin and eosin stain.

Radical prostatectomy was performed in cases of histological diagnosis of $\mathrm{PCa}$ at biopsy.

Histological examination recognized PCa (31 patients), BPH (30 patients), high-grade prostatic intraepithelial neoplasia (HGPIN, 13 patients), prostate adenoma (PA, 5 patients) and inflammation.

BPH was defined a non neoplastic increase of glandular and/or stromal components of the prostatic glands clinically characterized by enlargement of the gland, while PA was defined a prominent nodular proliferation of crowded benign small to medium-sized glands with inconspicuous nuclei.

Since the purpose of the present study was to detect differences in the serum proteomic profiles of $\mathrm{PCa}$ and
$\mathrm{BPH}$, all cases of HGPIN and PA were excluded. Furthermore, others 11 cases were not analyzed due to problems occurred during serum processing. Then, the analysis was performed on a total of 61 cases from the initial 90 patients enrolled. Clinical data of the patients analyzed are shown in Table 8.

Tumors were stratified according to the TNM classification [35] and Gleason grading system [36]: 25 cases were organ-confined tumor (pT1-pT2) and 6 cases were non-organ confined tumor (pT3); 14 cases were graduated as Gleason score $<7$ and 7 cases with Gleason score $\geq 7$.

\section{Serum samples}

Before prostatic biopsy, venous blood was collected into vacutainer serum separation tubes and allowed to clot at room temperature for 1 hour. Serum was separated by centrifugation at $2,000 \times \mathrm{g}$ for $10 \mathrm{~min}$ at $4^{\circ} \mathrm{C}$. After the addition of a protease inhibitor cocktail (Sigma-Aldrich) to prevent protein enzymatic breakdown or modifications, 
Table 7 Proteins differentially expressed in the absence of inflammation in PCa vs BPH

\begin{tabular}{|c|c|c|c|c|c|c|c|}
\hline Spot $n^{\circ}$. & Acc. $n^{\circ}$. & Protein full name & Mass (Da) & Score & $\mathrm{N}^{\circ}$ matchs/signif. matchs & $\mathrm{N}^{\circ}$ seq./signif. seq. & $\begin{array}{c}\text { Expression } \\
\text { change }\end{array}$ \\
\hline $\bar{A} 1$ & P00734 & Prothrombin & 71475 & 122 & $29 / 11$ & $8 / 5$ & $\uparrow$ \\
\hline$A 2$ & P00734 & Prothrombin & 71475 & 31 & $17 / 2$ & $6 / 2$ & $\uparrow$ \\
\hline A3 & POCOL5 & Complement C4-B (fragment) & 194170 & 2320 & $117 / 90$ & 20/17 & $\uparrow$ \\
\hline A4 & P01024 & Complement C3 (fragment) & 188569 & 1531 & $134 / 78$ & $54 / 36$ & $\uparrow$ \\
\hline A5 & P01024 & Complement C3 (fragment) & 188569 & 209 & $27 / 12$ & $15 / 6$ & $\uparrow$ \\
\hline A6 & P00738 & Zinc-alpha-2-glycoprotein & 45861 & 1037 & $95 / 61$ & 20/17 & $\uparrow$ \\
\hline A7 & P01024 & Complement C3 (fragment) & 188569 & 46 & $9 / 3$ & $6 / 3$ & $\uparrow$ \\
\hline A8 & P01024 & Complement C3 (fragment) & 188569 & 69 & $24 / 8$ & $7 / 5$ & $\uparrow$ \\
\hline A9 & P02790 & Hemopexin & 52385 & 1160 & $310 / 114$ & $30 / 21$ & $\downarrow$ \\
\hline A10 & P01008 & Antithrombin-III & 53025 & 542 & $136 / 50$ & $26 / 13$ & $\downarrow$ \\
\hline A11 & P36955 & Pigment epithelium-derived factor & 46454 & 166 & $33 / 15$ & $10 / 8$ & $\downarrow$ \\
\hline $\mathrm{A} 12$ & P36955 & Pigment epithelium-derived factor & 46454 & 422 & $61 / 35$ & $12 / 10$ & $\downarrow$ \\
\hline A13 & P00738 & Haptoglobin & 45861 & 437 & $52 / 31$ & $8 / 8$ & $\downarrow$ \\
\hline A14 & P00738 & Haptoglobin & 45861 & 871 & $90 / 52$ & $20 / 15$ & $\downarrow$ \\
\hline A15 & PODJI8 & Serum amyloid A-1 protein & 13581 & 111 & $17 / 8$ & $8 / 2$ & $\downarrow$ \\
\hline A16 & PODJI8 & Serum amyloid A-1 protein & 13581 & 244 & $34 / 22$ & $9 / 6$ & $\downarrow$ \\
\hline
\end{tabular}

Protein names in italic: proteins found also in the previous comparison in the presence of inflammation (Tables 5 and 6).

Protein names in bold: proteins not previously identified in presence of inflammation.

samples were divided into aliquots and kept frozen at $-80^{\circ} \mathrm{C}$ until use. A quality control sample (QC) was prepared by pooling an equal amount of serum from healthy donors. The QC sample was used to assess the reproducibility of each SELDI-ToF-MS experiment and as control for each obtained protein profile.

\section{Serum immunodepletion}

The presence of highly abundant proteins can interfere with the resolution and sensitivity of the proteomic techniques used to analyse the serum profiles. For this reason, serum samples were depleted by immunoaffinity chromatography using a Multiple Affinity Removal System

Table 8 Clinical data of enrolled patients

\begin{tabular}{lll}
\hline & PCa $(\mathbf{n}=\mathbf{3 1})$ & BPH $(\mathbf{n}=\mathbf{3 0})$ \\
\hline Median age (years) & 67 & 68 \\
PSA (range ng/mL) & $0.20-25.00$ & $0.80-34.36$ \\
Gleason score & \\
G $<7$ & 14 & $/$ \\
G $\geq 7$ & 17 & $/$ \\
Tumor clinical stage & & \\
T1 & 5 & $/$ \\
T2 & 20 & $/$ \\
T3 & 6 & \\
Inflammation & & 11 \\
Absence & 10 & 19 \\
Presence & 21 & \\
\hline
\end{tabular}

(MARS) column $(4.6 \mathrm{~mm}$ ID $\times 100 \mathrm{~mm}$, Agilent Technologies Inc., CA, USA) containing antibodies against the six most abundant serum proteins: albumin, IgG, IgA, transferrin, haptoglobin and alpha-1-antitrypsin. The depletion is expected to remove about $88-92 \%$ of the total protein content. Removal was performed according to the recommendations of the manufacturer. Briefly, $200 \mu \mathrm{L}$ of diluted sample were injected in a Beckman System Gold HPLC (Beckman Coulter, Fullerton, CA, USA). The lowabundance protein fractions eluted were aliquoted and stored at $-20^{\circ} \mathrm{C}$ until analysis. The QC was also depleted following the same procedure.

\section{SELDI-ToF-MS analysis}

A SELDI-ToF mass spectrometer Series 4000 (Bio-Rad Laboratories Inc., Hercules, CA, USA) was used to analyse the depleted serum samples. After some tests, the H50 (reverse-phase) ProteinChip Array, a surface able to selectively bind proteins with hydrophobic residues, gave the best serum profiles in terms of proteins number and resolution, so was selected for our experiments.

The analysis was performed as described in Monari et al. [37]. Shortly, depleted serum sample $(20 \mu \mathrm{L})$ was mixed with ProteinChip binding buffer $(110 \mu \mathrm{L})$ containing $10 \%$ acetonitrile $(\mathrm{ACN})$ and $0.1 \%$ trifluoroacetic acid (TFA), and loaded onto pre-equilibrated H50 ProteinChip Array spot surfaces. After incubation, saturated sinapinic acid solution was applied to each spot and samples were analyzed with two different reading protocols optimized for low and high MW (laser energy 
$2500 \mathrm{~nJ}$ and $5000 \mathrm{~nJ}$, respectively). The protein mass spectra were generated using an average of 901 laser shot, and the "All-in-one protein standard" (Bio-Rad) was used to generate a protein standard spectrum for mass accuracy calibration, for both reading protocols.

ProteinChip Data Manager 3.0 software (Bio-Rad) was employed for statistical analysis; the spectra were calibrated, baseline subtracted, mass aligned and normalized by total ion current in the range of $2-30 \mathrm{kDa}$ and 30 $100 \mathrm{kDa}$ for low and high MW, respectively. Poor quality spectra with a normalization factor greater than twice the median value were excluded. Supervised clustering was performed using the following settings: 5 times signal-to-noise $(\mathrm{S} / \mathrm{N})$ ratio, 3 times $\mathrm{S} / \mathrm{N}$ valley depth, $20 \%$ min peak threshold in the first pass for peaks identification, and 2 times $\mathrm{S} / \mathrm{N}$ ratio on the second pass for cluster completion.

To asses reproducibility the coefficient of variation (\% $\mathrm{CV}$ ) of peaks obtained from QC sample replicates were used. The pooled\% CV mean was $19.08 \%$ indicating that no analytical bias was present during the experiment.

After clusters identification, Student $t$-tests were performed and a p-value $\leq 0.05$ was accepted as statistically significant.

\section{Two-dimensional gel electrophoresis}

The immunodepleted serum samples, precisely the lowabundance protein fractions eluted, were first bufferexchanged using $20 \mathrm{~mm}$ Tris- $\mathrm{HCl}, \mathrm{pH}$ 7.4, by $5 \mathrm{kDa} \mathrm{MW}$ cut-off spin concentrators (Agilent Technologies). The samples were subjected to 3 cycles of buffer addition, with centrifugation at $7,500 \times \mathrm{g}$ at $10^{\circ} \mathrm{C}$ for $20 \mathrm{~min}$ every time.

Protein concentration was determined by the Bradford method [38], using the Protein Assay Dye Reagent (BioRad). Eighty micrograms of proteins were diluted to $300 \mu \mathrm{L}$ with a rehydration buffer composed of $6 \mathrm{M}$ urea, $2 \mathrm{M}$ thiourea, 4\% CHAPS, $25 \mathrm{mM}$ dithiothreitol (DTT), $0.2 \%$ ampholytes, and loaded onto $17 \mathrm{~cm}$ immobilized pH-gradient (IPG) strips, $\mathrm{pH}$ range 4-7 (Ready Strip ${ }^{\mathrm{Tm}}$, Bio-Rad). Proteins were separated in first dimension through isoelectric focusing at $20^{\circ} \mathrm{C}$, by an initial step of rehydration at $50 \mathrm{~V}$ for $12 \mathrm{~h}$, followed by a second step at $250 \mathrm{~V}$ for $15 \mathrm{~min}$, ramping up to $10.000 \mathrm{~V}$ for $3 \mathrm{~h}$ and finally focusing to reach $75.000 \mathrm{~V}$-h.

Subsequently, the strips were equilibrated by incubation for $15 \mathrm{~min}$ at room temperature, first with $1 \%$ DTT and then with $2.5 \%$ iodoacetamide, both dissolved in equilibration buffer containing $6 \mathrm{M}$ urea, $2 \%$ sodiumdodecyl-sulphate (SDS), 30\% glycerol, $50 \mathrm{mM}$ Tris- $\mathrm{HCl}$ pH 8.8 and trace of bromophenol blue. Second dimension separation was achieved by SDS-PAGE (SDS-polyacrylamide gel electrophoresis), using 8-16\% acrylamide gradient gel and a running buffer composed of $192 \mathrm{mM}$ glycine, $0.1 \%$ SDS and $25 \mathrm{mM}$ Tris- $\mathrm{HCl}, \mathrm{pH}$ 8.3. The equilibrated strips were embedded into a solution of $0.5 \%$ agarose on the top of the gel and electrophoresis was performed at $80 \mathrm{~mA} /$ gel for the first $30 \mathrm{~min}$, then the voltage increased to $500 \mathrm{~V}$ until the dye font reached the bottom of the gel. After 2-DE, proteins were visualized by a Silver nitrate staining protocol, as previously reported in detail [39].

Then, the gels were acquired using a GS-800 calibrated densitometer (Bio-Rad) and the gel images were exported to the PDQuest 2-D Image Analysis software, version 7.3.1. (Bio-Rad). This software compares 2-DE gel images, identifying differential protein expression by the detection of increase or decrease protein spot on the basis of their staining intensities.

In the present study, the differentially expressed protein spots were excised and "in-gel" trypsin digested, as previously fully described [39].

\section{Protein identification by LC MS/MS}

Obtained peptides were vacuum concentrated and then were dissolved in $10 \mu \mathrm{L}$ of Buffer A, composed of $3 \%$ ACN with $0.1 \%$ Formic Acid (FA). Digested peptides $(4 \mu \mathrm{L})$ were analyzed by the 6520 Accurate-Mass ESI-QToF coupled with a 1200 Nano HPLC-Chip microfluidic device (Agilent Technologies). Sample separation was performed as previously described figure In brief, the samples were loaded from the autosampler into the Chip enrichment column (Zorbax C18, $4 \mathrm{~mm} \times 5 \mu \mathrm{m}$ i.d., Agilent Technologies) by a capillary pump, with a loading flow of $4 \mu \mathrm{L} / \mathrm{min}$ using Buffer A. Nitrogen was used as the nebulising gas. A separation column (Zorbax C18, $43 \mathrm{~mm} \times 75 \mu \mathrm{m}$ i.d., Agilent Technologies) was used for peptide separation, setting the analytical flow rate at $0.4 \mu \mathrm{L} / \mathrm{min}$. Elution was obtained with Buffer B $(97 \%$ ACN, 0.1\% FA). Total run time was $40 \mathrm{~min}$.

Protein-identification peak lists were generated using Mascot server (Matrix Science, UK. Mascot 2.4). SwissProt protein database (SwissProt 2013_04) was selected, specifying the following parameters: Homo sapiens taxonomy, parent ion tolerance $\pm 20 \mathrm{ppm}, \mathrm{MS} / \mathrm{MS}$ error tolerance $\pm 0.1 \mathrm{Da}$, alkylated cysteine as fixed modification, oxidized methionine as variable modification, and two potential missed trypsin cleavages. Proteins were considered identified with at least 2 unique peptides.

\section{Abbreviations}

PCa: Prostate cancer; PSA: Prostate-specific antigen; BPH: Benign prostatic hyperplasia; SELDI-ToF-MS: Surface enhanced laser desorption/ionization time of flight - mass spectrometry; 2-DE: Two-dimensional gel electrophoresis; LC-MS/MS: Liquid chromatography MS/MS; DRE: Digital rectal exploration; TRUS: Trans-rectal ultrasound guided prostate biopsy; MW: Molecular weight; HGPIN: High-grade prostatic intraepithelial neoplasia; PA: Prostate adenoma; QC: Quality control; S/N: Signal-to-noise; CV: Coefficient of variation; DTT: Dithiothreitol; SDS: Sodium-dodecyl-sulphate; ACN: Acetonitrile; FA: Formic acid. 


\section{Competing interests}

The authors declare that they have no competing interests.

\section{Authors' contributions}

SB designed the study, performed immunodepletion of serum and drafted the manuscript. LRB performed histological analysis for each histological specimen. EM carried out SELDI-TOF-MS analysis and performed statistical analysis. EB performed bi-dimensional gel electrophoresis and helped to draft the manuscript. AC performed protein identification by mass spectrometry and helped in SELDI-TOF-MS experiments. TO and AT provided useful advices to improve the study and revised the manuscript. FB participated in samples collection and carried out samples preparation for mass spectrometry analysis. MCS was responsible for patient's recruitment and samples collection. GB participated in the design of the study and supervised the work. All authors read and approved the final manuscript.

\section{Acknowledgments}

The authors thank "Fondazione Cassa di Risparmio di Vignola" for financial support.

\section{Author details}

'Department of Diagnostic Medicine, Clinic and Public Health, Proteomic Lab, University Hospital of Modena and Reggio Emilia, Via del Pozzo 71, 41124 Modena, Italy. ${ }^{2}$ Section of Pathologic Anatomy, University Hospital of Modena and Reggio Emilia, Via del Pozzo 71, 41124 Modena, Italy. ${ }^{3}$ Department of Biochemistry, Medical Faculty, Akdeniz University, Antalya, Turkey. ${ }^{4}$ Department of Urology, University Hospital of Modena and Reggio Emilia, Via del Pozzo 71, 41124 Modena, Italy.

Received: 13 March 2014 Accepted: 30 May 2014

Published: 9 June 2014

\section{References}

1. Larkin SE, Zeidan B, Taylor MG, Bickers B, Al-Ruwaili J, Aukim-Hastie C, Townsend PA: Proteomics in prostate cancer biomarker discovery. Expert Rev Proteomics 2010, 7:93-102.

2. You J, Cozzi P, Walsh B, Willcox M, Kearsley J, Russell P, Li Y: Innovative biomarkers for prostate cancer early diagnosis and progression. Crit Rev Oncol Hematol 2010, 73:10-22.

3. Al-Ruwaili JA, Larkin SET, Zeidan BA, Taylor MG, Adra CN, Aukim-Hastie CL, Townsend PA: Discovery of serum protein biomarkers for prostate cancer progression by proteomic analysis. Cancer Genomics Proteomics 2010, 7:93-103.

4. Jemal A, Siegel R, Ward E, Hao Y, Xu J, Thun MJ: Cancer statistics, 2009. CA Cancer J Clin 2009, 59:225-249.

5. Beduschi MC, Oesterling JE: Percent free prostate-specific antigen: the next frontier in prostate-specific antigen testing. Urology 1998, 51:98-109.

6. Klein LT, Lowe FC: The effects of prostatic manipulation on prostatespecific-antigen levels. Urol Clin North Am 1997, 24:293-297.

7. McLerran D, Grizzle WE, Feng Z, Bigbee WL, Banez LL, Cazares LH, Chan DW, Diaz J, Izbicka E, Kagan J, Malehorn DE, Malik G, Oelschlager D, Partin A, Randolph T, Rosenzweig N, Srivastava S, Srivastava S, Thompson IM, Thornquist M, Troyer D, Yasui Y, Zhang Z, Zhu L, Semmes OJ: Analytical validation of serum proteomic profiling for diagnosis of prostate cancer: sources of sample bias. Clin Chem 2008, 54:44-52.

8. Qu Y, Adam BL, Yasui Y, Ward MD, Cazares LH, Schellhammer PF, Feng Z, Semmes OJ, Wright GL Jr: Boosted decision tree analysis of surfaceenhanced laser desorption/ionization mass specral serum profiles discriminates prostate cancer from noncancer patients. Clin Chem 2002, 48:1835-1843.

9. Goo YA, Goodlett DR: Advances in proteomic cancer biomarker discovery. J Proteomics 2010, 73:1839-1850.

10. Lin JF, Xu J, Tian HY, Gao X, Chen QX, Gu Q, Xu GJ, Song JD, Zhao FK: Identification of candidate prostate cancer biomarkers in prostate needle biopsy specimens using proteomic analysis. Int J Cancer 2007, 121:2596-2605.

11. Alaiya A, Roblick U, Egevad L, Carlsson A, Franzén B, Volz D, Huwendiek S, Linder S, Auer G: Polypeptide expression in prostate hyperplasia and prostate adenocarcinoma. Anal Cell Pathol 2000, 21:1-9.

12. Cazares LH, Adam BL, Ward MD, Nasim S, Schellhammer PF, Semmes OJ, Wright GL Jr: Normal, bening, preneoplastic, and malignant prostate cells have distinct protein expression profiles resolved by surface enhanced laser desorption/ionization mass spectrometry. Clin Cancer Res 2002, 8:2541-2552.

13. Reed $A B$, Parekh DJ: Biomarkers for prostate cancer detection. Expert Rev Anticancer Ther 2010, 10:103-114.

14. Parekh DJ, Ankerst DP, Troyer D, Srivastava S, Thompson IM: Biomarkers for prostate cancer detection. J Urol 2007, 178:2252-2259.

15. Adam BL, Qu Y, Davis JW, Ward MD, Clements MA, Cazares LH, Semmes OJ, Schellhammer PF, Yasui Y, Feng Z, Wright GL Jr: Serum protein fingerprinting coupled with a pattern-matching algorithm distinguishes prostate cancer from benign prostate hyperplasia and healthy men. Cancer Res 2002, 62:3609-3614.

16. Ornstein DK, Rayford W, Fusaro VA, Conrads TP, Ross SJ, Hitt BA, Wiggins WW, Veenstra TD, Liotta LA, Petricoin EF 3rd: Serum proteomic profiling can discriminate prostate cancer from benign prostates in men with total prostate specific antigen levels between 2.5 and $15.0 \mathrm{ng} / \mathrm{ml}$. J Urol 2004, 172:1302-1305.

17. Ummanni R, Junker H, Zimmermann U, Venz S, Teller S, Giebel J, Scharf C, Woenckhaus C, Dombrowski F, Walther R: Prohibitin identified by proteomic analysis of prostate biopsies distinguishes hyperplasia and cancer. Cancer Lett 2008, 266:171-185.

18. Wang W, Bergh A, Damber JE: Morphological transition of proliferative inflammatory atrophy to high grade intraepithelial neoplasia and cancer in human prostate. Prostate 2009, 69:1378-1386.

19. Abdel-Muguid TA, Mosli HA, Al-Maghrabi JA: Prostate inflammation. Association with benign prostatic hyperplasia and prostate cancer. Saudi Med J 2009, 30:1563-1567.

20. Mosli HA, Abdel-Meguid TA, Al-Maghrabi JA, Kamal WK, Saadah HA, Farsi HM: The clinicopathologic patterns of prostatic diseases and prostate cancer in Saudi patients. Saudi Med J 2009, 30:1439-1443.

21. Mantovani A, Allavena P, Sica A, Balkwill F: Cancer-related inflammation. Nature 2008, 454:436-444.

22. Byrne JC, Downes MR, O'Donoghue N, O'Keane C, O'Neill A, Fan Y, Fitzpatrick JM, Dunn M, Watson RW: 2D-DIGE as a strategy to identify serum markers for the progression of prostate cancer. J Proteome Res 2009, 8:942-957.

23. Bellei E, Bergamini S, Monari E, Fantoni LI, Cuoghi A, Ozben T, Tomasi A: High-abundance proteins depletion for serum proteomic analysis: concomitant removal of non-targeted proteins. Amino Acids 2011, 40:145-156.

24. Pace G, Di Massimo C, De Amicis D, Vicentini C, Tozzi Ciancarelli MG: Inflammation and endothelial activation in benign prostatic hyperplasia and prostate cancer. Int Braz J Urol 2011, 37:617-622.

25. Chechlinska M, Kowalewska M, Nowak R: Systemic inflammation as a confounding factor in cancer biomarker discovery and validation. Nature Rev 2010, 10:2-3.

26. Balkwill F, Mantovani A: Inflammation and cancer: back to Virchow? Lancet 2001, 357:539-545.

27. Liu C: Serum Amyloid A protein in clinical cancer diagnosis. Pathol Oncol Res 2012, 18:117-121.

28. Menschikowski M, Hagelgans A, Fuessel S, Mareninova OA: Serum Amyloid $A$, phospholipase $A_{2}-\| \mathrm{A}$ and $C$-reactive protein as inflammatory biomarkers for prostate diseases. Inflamm Res 2013, 62(12):1063-1072.

29. Tolosano E, Altruda S: Hemopexin: structure, function, and regulation. DNA Cell Biol 2002, 21(4):297-306.

30. Debruyne EN, Vanderschaeghe D, Van Vlierberghe $H$, Vanhecke A, Callewaert N, Delanghe JR: Diagnostic value of the hemopexin N-glycan profile in hepatocellular carcinoma patients. Clin Chem 2010, 56(5):823-831.

31. O'Reilly MS: Antiangiogenic antithrombin. Semin Thromb Hemost 2007, 33(7):660-666.

32. Cao Y, Lundwall A, Gadaleanu V, Lilja H, Bjartell A: Anti-thrombin is expressed in the benign prostatic epithelium and in prostate cancer and is capable of forming complexex with prostate-specific antigen and human glandular kallikrein 2. Am J Pathol 2002, 161:2053-2063.

33. Honegger $\mathrm{H}$, Anderson $\mathrm{N}$, Hewitt LA, Tullis JL: Antithrombin III profiles in malignancy, relationship primary tumors and metastatic sites. Thromb Haemost 1981, 46(2):500-503.

34. Hong SK, Ko DW, Park J, Kim IS, Doo SH, Yoon CY, Park H, Lee WK, Kim DS, Jeong SJ, Byun SS, Lee SE: Alteration of antithrombin III and D-dimer levels in clinically localized prostate cancer. Korean J Urol 2010, 51:25-29. 
35. Edge S, Byrd DR, Compton CC, Fritz AG, Green FL: AJCG Cancer Staging Handbook. In AJCC Cancer Staging Manual. 7th edition. New York: SpringerVerlag; 2010:525-538.

36. Epstein J: An update of the Gleason Grading System. J Urol 2010, 183:433-440.

37. Monari E, Casali C, Cuoghi A, Nesci J, Bellei E, Bergamini S, Fantoni LI, Natali $P$, Morandi U, Tomasi A: Enriched sera protein profiling for detection of non-small cell lung cancer biomarkers. Proteome Sci 2011, 9:55.

38. Bradford MM: A rapid and sensitive method for the quantitation of microgram quantities of protein utilizing the principle of protein-dye binding. Anal Biochem 1976, 72:248.

39. Bellei E, Rossi E, Lucchi L, Uggeri S, Albertazzi A, Tomasi A, lannone A: Proteomic analysis of early urinary biomarkers of renal changes in type 2 diabetic patients. Proteomics Clin Appl 2008, 2:478-491.

doi:10.1186/1477-5956-12-32

Cite this article as: Bergamini et al.: Inflammation: an important

parameter in the search of prostate cancer biomarkers. Proteome Science 2014 12:32.

\section{Submit your next manuscript to BioMed Central and take full advantage of:}

- Convenient online submission

- Thorough peer review

- No space constraints or color figure charges

- Immediate publication on acceptance

- Inclusion in PubMed, CAS, Scopus and Google Scholar

- Research which is freely available for redistribution 